\title{
存量规划时代城市规划师的角色与技能 两个海外案例的启示
}

The Transitional Role and Skills for Urban Planners in the Era of Inventory Planning: Two Overseas Cases

摘要: 世界范围内的城市规划实践都已面临从 “增量规划”向“存量规划”的转型。对于城市 规划师而言, 必须理解这种转型的本质, 将自身 社会角色逐步向规划决策和执行过程中的组织协 调者转变, 并强化在制度分析、政策设计、说服 沟通等方面的专业技能。本文选取孟加拉国和英 国两个典型案例，对当前发展中国家和发达国家 存量规划实践中规划师的角色转变与技能需求进 行了详细的解读, 进一步明确其在实践中的内容 和作用, 为 “存量规划”时代中国规划师的职业 发展方向探讨提供有价值的经验。

Abstract: The nature and tasks of urban planning have been changed significantly since the emergence of the era of inventory planning. For urban planners, the working role is becoming organizers and coordinators during the decision making process of urban affairs, while a series of new skills of analysis, communication and persuasion should be more crucial for planners' professional development. This paper summarizes the role transition and skill requirements through two case studies in Bangladesh (typical case of developing countries) and the UK (typical case of developed countries), in order to gain valuable experience for the career development of Chinese urban planners in the era of inventory planning.

关键词: 存量规划; 规划师; 社会角色; 职业技能; 转变

Keywords: Inventory Planning; Planner; Social Role; Professional Skill; Transition

国家自然科学基金《乡村移民回流对西部地区县 域城镇空间结构的影响研究》(51308044) 资助

作者: 钱云, 北京林业大学园林学院城市规划系, 副教授。qybjfu@126.com

\section{1 存量规划时代的城市问题}

现代城市规划是伴随西方工业化以来城市建设快速扩张中产生的一系列城 市问题而出现的。由于工业时代城市规模远超既往、功能复杂, 易造成建设增 长中社会经济文化等方面的不均衡发展, 因而必须要求在建设之初从整体对资 源利用的方式, 包括用地分类布局、基础设施配置和空间形态塑造等进行统筹 安排 ${ }^{[1]}$ 。城市规划师长期饰演建设增长中 “运筹帷幄者” 的角色, 通常以精英 主义的心态, 遵循美学和科学方面的理念, 依托政府颁布的一系列强制执行的 法令、规范和蓝图, 自上而下地对各类资源利用进行强力控制和引导, 力图实 现资源利用效率最高、共同利益最大化 ${ }^{[2]}$ 。

然而随着当代文明的进一步发展, 城市尽管依然是国家和区域发展的引擎, 但其社会生产方式发生了显著的转变：“发展”与 “增长”的观念不再紧密相 关, 而是期望在尽量控制资源消耗的条件下, 通过内在制度的调整, 降低各类 资源交易成本, 促进更频繁的人际交互和思想碰撞过程, 从而生成持续发展的 新动力 ${ }^{[2-7]}$ 。社会大背景的变革决定了城市规划实践的重心面临从 “增量规划” 转向 “存量规划” 的局面。在新的时代, 无论在发达国家还是发展中国家, 城 市问题大多不再与建设增长相关联, 而更主要的来自于因社会多元分化带来的 各类社会群体需求和资源分配的矛盾, 较为典型的包括 : 城市基础设施和公共 服务的数量、类别和区位无法适应居民的需求 ; 城市生活质量提升对自然环境 造成不可逆的破坏; 城市居民贫富差距的增加以及弱势群体逐步边缘化带来的 社会不稳定; 多元文化的高度混杂带来的社区意识模糊等 ${ }^{[8,9]}$ 。中国作为当下全 世界城市发展变革最为剧烈的地区, 上述诸多矛盾的激化已十分显著, 如果长 期存在, 将严重威胁到城市生长体系的可持续性, 丧失城市的吸引力和竞争力。 毫无疑问, 中国城市已经步人存量规划逐步成为主流的时代, 对城市规划实践 工作转型转向的讨论应不再直于 “是否应当”, 而更多关注于 “如何去做” ${ }^{[10]}$ 。

\section{2 存量规划时代城市规划师的新要求}

\section{1 当代城市存量规划的新任务}

在不再以空间扩张为核心任务的存量规划实践中, 传统增量规划中利用非 市场手段调节实现 “共同利益最大化” 的简单逻辑正在面临诸多困难 : 一方面 
自上而下的机械控制与全球化市场环境日益完善下资源调配 的方式格格不人; 另一方面在高度多元化的当代社会, 各阶 层和群体的民众都会有其各自的声音及特殊利益, 单一自上 而下的政府行为势必无法满足多元社会需求, 尤其是获取资 源途径更为缺乏的各类弱势群体的需求 ${ }^{[11-14]}$ 。因此存量规划 时代的规划实践中, 最重要的任务包括两方面 : 一是动员并 容纳各方社会角色的参与来应对城市问题, 设法激活各种存 量资源; 二是促进更为广泛的民主规划决策过程, 以各种灵 活的方式进行存量资源的再分配, 以更好地适应来自不同民 众群体的需求 ${ }^{[15-18]}$ 。

\section{2 存量规划时代规划师的新角色和技能}

在存量规划的任务下, 城市规划师势必将更为深度地融 人, 而不再仅仅是预测和遥控城市的社会经济运行实践。在 实践过程中, 规划师的角色往往是更为综合性的 : 在研判城 市问题的矛盾焦点时是出色的倾听者和观察员; 在组织各方 谈判协商的过程中是公正的利益协调人及创造性解决方案的 提出者; 在激发社会存量资源及推动对策执行的过程中是良 好的说服者。

因此, 新时期城市规划师迫切需要强化掌握一系列曾经 被长期忽略的职业技能, 主要包括 : 在纷繁复杂的现状困境 中开展有效调查的能力; 厘清利益分歧各方的诉求, 识别矛 盾的关键所在的分析能力; 面对利益分歧保持开放的态度及 提出有建设性的提议的能力; 以及怀有妥协和解决问题的意 愿、耐心和恒心等。

当然, 这并不意味着应忽视增量规划时代规划师所掌握 的关于城市发展各种客观规律的理论知识——事实上在生态 城市营造、保障性住房建设、城市公共设施完善等新时代规 划所着重关注的方面, 增量规划时代所积累的专业技术依然 无法替代 ${ }^{[9]}$ —现在要做的只是克服官僚主义, 打破依赖自 上而下的强制性控制这一固有观念, 通过沟通、协调以及包 容使得更多民众与团体都积极参与和融人到规划活动中来, 确保规划决策更为现实及易于推动 ${ }^{[19]}$ 。

\section{3 不同语境下城市规划师的新技能需求}

在城市化进程较早的欧美国家, 随着建设增长速度的放 缓, 有关 “存量资源再调整” 的倡导式规划、沟通式规划等 理念探讨已持续多年, 而近年来则已经在实践中有所突破, 积累了相当的经验 ${ }^{[20-22]}$ 。此外, 位于亚非拉世界的诸多欠 发达国家也在近年经历了前所未有的城市化进程, 作为 “后 发国家”, 其城市发展往往面临着传统与外来文化及制度冲 突、社会结构剧烈重组等更为复杂的环境, 因此在规划实 践中尽管套用西方传统的增量规划方法仍必不可少, 但存
量调整往往提前成为更加迫切的任务, 相关实践也已形成 一定的积累。

中国作为东亚新兴经济体的代表, 一方面正经历着与当 年西方国家较为类似但进程快得多的工业化一城市化进程, 另一方面也面临着更为复杂的综合矛盾。因此, 本文选择孟 加拉国首都达卡和英国首都伦敦两个案例, 详细探讨在存量 规划时代，欠发达和发达国家在城市规划实践中面临的新的 典型问题、可能的对策及城市规划师职业技能的新需求, 以 期进一步明确认识, 为存量规划时代中国规划师的职业发展 方向提供有价值的经验参考。

\section{3 基于沟通的双赢规划一一达卡贫民供水案例}

\section{1 项目背景与面临的困境}

孟加拉国是南亚重要的国家之一, 1971 年独立以来, 纺织等劳动密集型工业的发展吸引了大量乡村劳动力快速涌 人城市, 城市规模迅速扩大。首都达卡是世界上人口增长最 快的大城市之一, 1990-2005 年从 600 万增至 1200 万, 而 2025 年预计将达到 2000 万。由于外来移民大量快速涌人, 城市建设不堪重负, 长期以来至少有三分之一的达卡市民聚 集生活在各类贫民窟中, 严重缺乏基本的城市基础设施和公 共服务设施, 生活质量甚至远远不如乡村地区（图 1)。

在达卡为数众多的贫民窟中, 缺少有保障的清洁供水 一直是导致生活质量恶劣的核心问题之一。由于达卡贫民窟 规模过于巨大, 城市政府公共财力不足, 达卡供水和排污局 (DWASA: Dhaka Water Supply and Sewage Authority) 只提 供清洁用水给城市中的 “合法用户”。对于分散居住在贫民 窟中的居民, 长期以来由于他们不能证明其居住的合法性, 也无法为支付供水费用提供担保, 因此无法获得使用公共 清洁用水的权利, 不得不从住地附近受污染的水塘中取水 (图 2)。而对于 DWASA 而言, 由于城市供水范围有限,

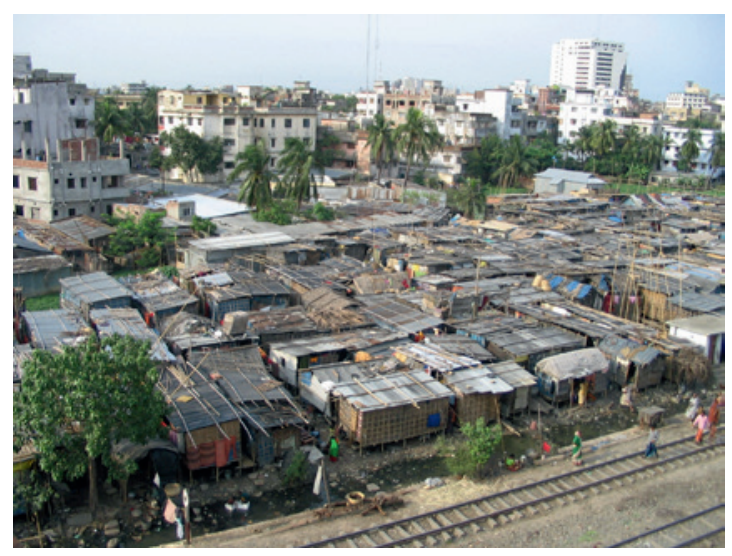

图 1 达卡城市中遍地可见的贫民窟

资料来源 : Final Report Preparation of Detailed Area Plan (DAP) for DMDP Area: Group-A, RAJUK 
供水的成本居高不下, 收取的有限费用也难以实现供水网络 的有效维护和拓展。

在达卡的历次城市规划中, 曾经多次提出过在贫民社区 建设供水设施的议题。但由于规划部门对贫民社区的用水需 求缺乏详尽的了解，始终无法对贫民用水点的建设提出有实 践意义的指导建议。

\section{2 非政府组织引领的规划实践过程}

面对这样的困境，非政府规划机构 “Dushtha Shasthya Kendra”（DSK）在促进城市贫民获得公共部门清洁供水的 过程中起到了至关重要的作用。DSK 的工作人员既包括对达 卡贫民区情况较为熟悉的有经验的城市规划师, 也有接受过 国际组织良好培训的社区工作者。DSK 的工作主要分为两个 阶段。第一个阶段是深人贫民窟社区，通过协助完善社区组 织建设; 充分了解真实的供水需求, 包括明确城市贫民愿意 付费使用城市清洁供水的意图、用水量需求和可承受的费用 等。第二个阶段是与政府的规划相关部门紧密合作，在条件 成熟的社区设计合理的供水线路和供水点，并敦促 DWASA 逐步启动建设; 此外 DSK 还帮助寻求到财政担保, 以防常 规水费无法收取时能继续维持供水。两项工作都持续了多年, 漫长的协商和在谈判中有效的沟通工作，不断建立了各方对 彼此的信任。经过多方努力，DWASA 在 1992-1994 年间 打破常规, 批准设立了两个位于卡尔扬普贫民窟的供水点。 DSK 通过持续的沟通, 组织当地居民选举产生供水管理委 员会, 负责供水设施的维护以及水费的及时收取。成功的管 理使得 DSK 预先准备的保证金从未被启用。先期实验充分 证明，只要保持政府、社区之间良好的沟通渠道，贫民窟居 民完全可以成为可信赖的付费用户。随后 DSK 开始致力将 这一可持续的模式推广到其他贫民窟。

对于 DWASA 来说, 由于供水范围的扩大, 增加了水 费收人, 降低了供水的单位成本, 形成一个双赢的局面。 因此自 1996 年以来, DWASA 主动成为这一计划的积极推 动者, 在达卡的 70 个贫民窟陆续设置了 88 个供水点, 满
足了约 20 万人的用水需求 (图 3), 并和城市规划部门合作, 完成了在 110 个贫民社区逐步提供供水服务的行动规划。 DSK 会陆续将担保用水的责任全部移交给当地贫民社区自 主管理而无需第三方担保。让这些社区自主完成付款有利 于增加他们的信誉度以及巩固其使用清洁供水资源的权利。

\section{3 达卡案例经验总结}

DSK 主导实现的达卡城市贫民供水问题的解决, 成功 地阐释了引入多方社会力量、民主协商解决分歧的过程对优 化公共服务供给体系的重要作用。在传统的自上而下规划体 系严重缺位的贫民社区，长期以来民众与公共服务部门之间 的沟通无法建立, 但规划师敏锐地发现了双方对于居住环境 提升的共同愿望, 在长时间磨合沟通、社区组织的完善和引 人第三方担保后, 最终形成了能较准确把握真实供需关系的 有效协商机制, 并通过实践不断深化相互信任, 确保了所制 定的规划策略真正持续有效。

可以看出, 存量规划中城市规划师作为分歧协调者, 需 要敏锐地捕捉不同群体的立场、既得利益和心态, 保持与 规划实践中各相关利益者之间的有效沟通，倾听各方观点， 消除疑虑和偏见, 促进交流与互动, 找到利益共同点, 并 有效地发掘和调动各方社会资源的潜力以推动规划决策的 执行。

\section{4 实现包容的援助规划一一伦敦社区规划案例}

\section{1 英国 “规划援助” ( planning aid) 运动兴起的背景}

在英国, 城市规划被公认为协调社会分歧、促进社会公 平的举措为时已久。近年来随着政府 “权力下放” 的过程, 本地社区在规划决策中的地位不断提升。规划决策在理念上 和程序上都更加强调包容性 (inclusion), 高度重视贫困、失 业和少数族裔等社会边缘 / 弱势群体的参与融人。然而在实 践中, 由于获取信息渠道、文化差异、社交网络等方面的差 异, 不同社会群体往往接收到的公共信息并不对称, 在表达 诉求、沟通协调方面的能力也不尽相同, 因此其在规划参与

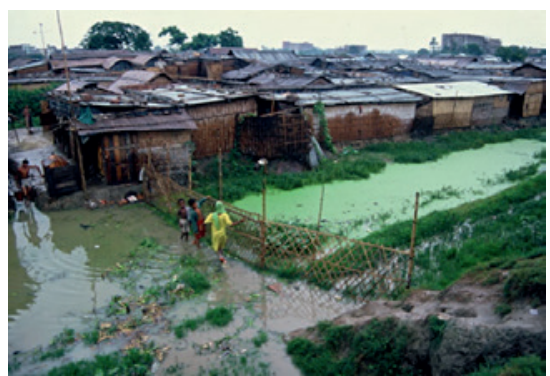

图 2 缺少清洁供水的达卡贫民窟

资料来源 : Final Report Preparation of Detailed Area Plan (DAP) for DMDP Area: Group-A, RAJUK
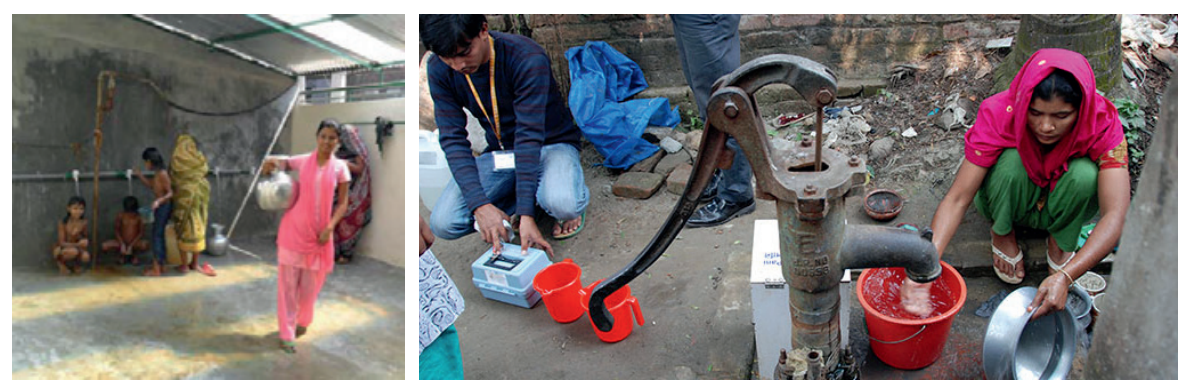

图 3 DSK 和 DWASA 共同建立的达卡贫民窟供水点

资料来源 : 左图 DSK Activity Report 2010 ; 右图 http://www.wsup.com/programme/where-we-work/bangladesh/ 
的过程中的作用也并不一致。事实上, 由于社会边缘群体本 身生存状态的缘故, 尽管在规划参与过程中未被主观区别对 待, 但客观上他们的声音仍往往被排斥 (exclusion) 或边缘 化 (marginalization), 从而影响了社会资源的公平分配。因 此, 城市规划师应当主动意识到权力关系在规划决策和实践 中的存在并努力抵消这种不均衡造成的负面影响。

规划援助作为一项自发运动致力于提升边缘群体在城 市规划事务中的参与和决策权, 在伦敦等城市已有 40 年的 发展历程, 并在全国各地均成立了相应的组织一一英格兰 规划援助组织 (Planning Aid England)、伦敦规划援助组织

(Planning Aid for London)、苏格兰规划援助组织（Planning Aid for Scotland)、威尔士规划援助组织 (Planning Aid Wales)、爱尔兰社区技术援助组织 (Community Technical Aid in Ireland）等。其中大部分由皇家规划师协会（RTPI） 来组织领导; 其组织成员由有资历的志愿工作者组成, 主要 包括城市规划师、建筑师和律师。

\section{2 工作内容和服务对象}

规划援助的工作主要是为城市规划方案中利益相关的 个人或团体提供专业的建议帮助。同时规划援助也为无经 济能力雇佣专业规划人员的个人或团体提供免费和独立的 专业规划指导。可获得上述免费规划服务援助的个人和团 体需满足一定的要求, 以确保其为真正需要援助的 “社会 边缘群体”（表 1)。

在伦敦为数庞大的废弃工厂和铁路沿线规划重建中, 规 划援助组织发挥了巨大的作用。规划援助工作者遇到的最大 困难就是与大量居住在这些地区的少数族裔民众、流浪者以 及吸毒人员充分接触。 2004 年, 规划援助运动共与 62 个民 间社区机构合作, 组织了各类研讨会, 协助社区居民充分了 解规划方案的意图, 例如专门为底层民众编写更加易懂和概 略的材料来解读官方的规划草案。一系列的举措有效地提升 了社区组织的受关注度, 并将边缘群体的意见以专业和现实 的方式提供给官方规划机构 (图 4)。

在具体的项目实践方面, 伦敦东区索马里中心（Somali Centre) 的扩建是最成功的案例之一。位于两条道路交叉口 的这一小型建筑是周边索马里移民聚居的社区公共服务中 心, 也是当地最为重要的休闲聚会和文化交流场所。由于原

\section{表 1 符合资格获取免费规划服务援助的个人和团体（伦敦）}

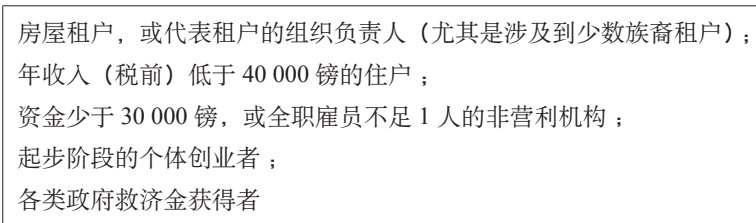

资料来源 : http://www.planningaidforlondon.org.uk/?idno=1
有建筑规模有限, 当地社区十分期望申请到政府公共事业补 助基金, 对索马里中心进行扩建。然而尽管政府相关资金充 足，但由于语言和技术方面的障碍，该社区民众面对规划部 门所要求提交的技术报告和繁琐的程序一筹莫展。在此时, 规划援助充分发挥了其效能, 为这一扩建工程提供了详尽的 技术报告并全程协助客户完成资金申请, 直到他们最终获得 资金。此外规划援助者还提出建议, 在靠近繁华街道一侧加 建一组临街商业建筑, 以获取可观的收人来支持社区中心的 长期运行费用。

\section{3 伦敦案例经验总结}

由此可见，尽管英国规划体系中对公众参与的高度强调 已历时多年, 但为了进一步提升规划决策的包容性、本土化 和有效性, 确保社会资源匮乏的弱势群体更充分的融人, 规 划援助等灵活方式必不可少。在实践中, 城市规划从业者以 志愿参与的方式, 能够突破法定规划的各种桎梏和技术门槛, 更充分地与民众进行沟通, 了解民众的实际需求, 打破其与 官方规划管理体系中的种种沟通障碍, 也有利于为亟需帮助 的城市边缘人群寻找特异化、量体裁衣的解决方案。

规划援助的实践是存量规划时代深人发掘社会需求和各 方资源潜力的有效尝试, 是建立规划实践中各相关利益者之 间有效协调机制的进一步完善和延伸。这也要求参与相关实 践的城市规划师具备更加出色的沟通与协调的技能, 以更包 容的心态、更强烈的社会融人意识和更具创造力的执行能力 来开展工作。

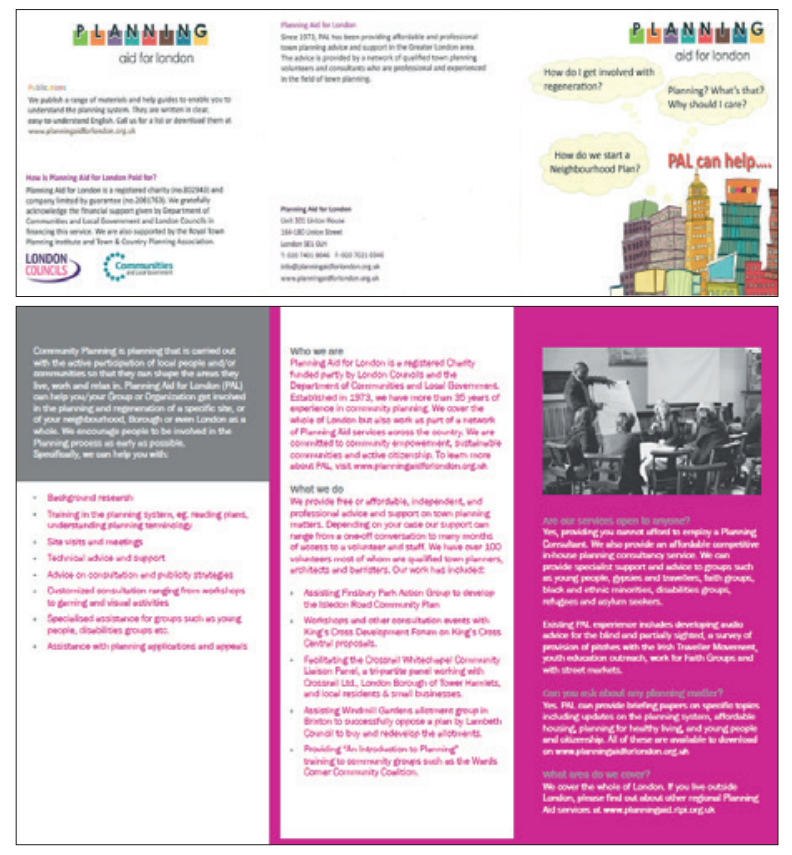

图 4 伦敦规划援助活动的部分宣传材料

资料来源 : http://www.planningaidforlondon.org.uk/?idno=679 


\section{5 结语与启示}

综上所述，鉴于存量规划时代城市规划的主要任务不 再主要关注建设增长, 而是重在多元社会需求与公共资源 使用的矛盾协调，相应的，城市规划师的社会角色势必从 技术精英、决策者, 转变为 “积极有效的协调组织者”, 在 规划实践中的职责不仅包括通过专业技能推动更为民主的 决策过程，还应涉及广泛动员社会资源以协助推动规划决 策的实施。

本文中孟加拉国的案例展现了在发展中国家, 城市规划 师如何作为民众和决策者之间沟通和相互信任的发起者, 实 现在自上而下规划体系缺少影响力的社区推动居住质量持续 提升的作用。而英国的案例则展现了在发达国家，城市规划 师如何以更灵活的工作方式，将原有专业化的规划体系进一 步融人民众、满足更小众、更广泛需求的过程。尽管两个案 例国家的发展阶段存在差异, 但都充分说明了在存量规划时 代，城市规划师的核心技能除了熟悉城市发展规律的相关理 论外, 还应更加强调有效的调查、沟通、协调与动员能力, 甚至推动城市发展中某些制度变革的能力等。

对于存量规划时代即将来临的中国而言, 相当数量城市 规划师的职业发展将面临挑战。由于固有体制的存在，在城 市规划人才培养、职业资格考核等方面，长期以来仍较多地 偏重强调工程技术能力, 在社会调查、问题分析、沟通交流 等诸方面缺漏甚多, 影响和协调社会资源方面的能力更是被 严重忽视。尽管近年来学术界和业界对存量时期城市规划师 的社会角色和职业技能转型的探讨已越发充分, 诸多共识也 逐步形成，但对其在具体实践中的作用仍缺少深刻的理解。 本文通过对不同国家相关规划实践中典型案例的审视, 对上 述转变的具体内容和作用进行详细探讨, 以期进一步明确认 识, 为未来中国城市规划人才培养和职业发展提供有价值的

\section{经验。UPI}

\section{参考文献}

[1] Hall P. Urban and Regional Planning[M]. 4th ed. London: Routledge, 2002.

[2] 赵燕菁. 存量规划: 理论与实践 [J]. 北京规划建设, 2014(4):153-156.

[3] Harvey D. The Condition of Postmodernity: An Enquiry into the Origins of Cultural Change [M]. Oxford; Cambridge, Mass., USA: Blackwell, 1990.

[4] Hall P. Modelling the Post-industrial City [J]. Future, 1997, 29(4/5): 311322.

[5] Meijir M. Growth and Decline of European Cities: Changing Positions of Cities in Europe [J]. Urban Studies, 1993, 30: 981-990.

[6] Castells M. The Informational City: Information Technology, Economic Restructuring and the Urban-Regional Process [M]. Oxford: Basil Blackwell, 1989

[7] Castells M. The Information Age: Economy, Society and Culture. Vol.1, The Rise of the Network Society [M]. Oxford: Basil Blackwell, 1996.

[8] 联合国人居署。全球化世界中的城市一一全球人类住区报告 2001[M]
北京：中国建筑工业出版社, 2004 .

[9] Hague C, Wakely P, Crespin J, Jasko C. Making Planning Work: A Guide to Approaches and Skills [M]. Michigan: Intermediate Technology Publications, 2006

[10] 施卫良, 邹兵, 金忠民, 等. 面对存量和减量的总体规划 [J]. 城市规划, 2014(11): 16-21.

[11] 石楠. 试论城市规划中的公共利益 [J]. 城市规划, 2004(6): 20-31.

[12] 苏腾, 曹珊. 城市规划中的公共利益困境 [J]. 规划师, 2007(8): 52-57.

[13] Friedmann J. Planning in the Public Domain: From Knowledge to Action [M]. Princeton: Princeton University Press, 1987

[14] 沈惠平, 黄兴生. 坚持公共政策的公共利益取向 [J]. 理论探讨, 2003(1): 86-88.

[15] Ward S. Planning and Urban Change [M]. London: Sage, 2004.

[16] 薛冰. 个人偏好与公共利益的形成一一兼论阿罗不可能 $[\mathrm{J}]$. 西北大学 学报, 2003(11): 79-83.

[17] 李阎鬼. 社会利益分化的城市规划策略探讨一一基于科学发展观的思 考 [J]. 现代城市研究, 2006(3): 10-14.

[18] 黄瓴, 许剑锋. 城市社区规划师制度的价值基础和角色建构研究 [J]. 规划师，2013(9): 11-16.

[19] 郭建, 孙惠莲. 公众参与城市规划的伦理意蕴 [J]. 城市规划, 2007(7): 56-61.

[20] Davidoff P. Advocacy and Pluralism in Planning [J]. Journal of the American Institute of Planners, 1965, 31(4): 331-338.

[21] Fainstein S. New Directions in Planning Theory [J]. Urban Affairs Review, 2000, 35(4): 451-478.

[22] Healey P. Collaborative Planning: Shaping Places in Fragmented Societies [M]. London: Macmillan, 1997. 